\title{
Effect of South African Quaternary Extenders on Early Compressive Strength
}

\author{
Abiodun Ebenezer Akinwale ${ }^{1}$, Bolanle Deborah Ikotun ${ }^{1}$, Ayo Samuel Afolabi² \\ ${ }^{1}$ Department of Civil \& Chemical Engineering, University of South Africa Florida Campus \\ Johannesburg, South Africa \\ ${ }^{2}$ Department of Chemical, Metallurgical \& Materials Engineering \\ Botswana International University of Science \& Technology \\ Botswana \\ akinaae@unisa.ac.za; ikotubd@unisa.ac.za; afolabia@biust.ac.bw
}

\begin{abstract}
In this paper, the embedded reinforcement in concrete are usually sheltered from corrosion by a thick oxide layer formed on their exteriors because of the highly alkalinity of the exposed environment of the adjoining concrete which thus affect both the strength and durability of the affected structures. In spite of this protective mechanism, corrosion of the reinforcement remains one of the biggest common durability challenges. On the other hand, this destructive phenomenon affects not only the durability but the strength of the affected structures. However, the use of cementitious blends which has generated huge research interest for many years has greatly increased due to environmental concern and awareness. The present study focusses on investigating the effect of quaternary combination of South African supplementary cementitious materials on the early strength development of the concrete with a view to encourage local usage of these power plant by-products and to encourage reduction of $\mathrm{CO}_{2}$ emission during the cement production.
\end{abstract}

Keywords: Cementitious blends, Compressive strength, early strength development, quaternary, supplementary materials, extenders.

\section{Introduction and Background}

Compressive strength is one of the most important design parameters to structural engineers because it acts as a drive in the design process towards satisfying the limit state design requirements; obviously, it has a direct influence on the project's cost.[1] Cementitious blends can be used to reduce the associated cost of concrete production and assist in producing concrete that is environmentally friendly, since the production of cement creates substantial amounts of pollution through release of high volume of $\mathrm{CO}_{2}$ emission from cement production has resulted in a great concern to researchers in concrete industry and cement production which has provided a number of investigation on cement production with extenders [2]. Thus the use of supplementary cementitious blends which has generated huge interest within the research circle for many years has greatly increased due to environmental concern and awareness.

The usage of these cementitious blends thus became imperative and attractive due to its simplicity and relative cost advantage [3] as they are used for various purposes such as improvement in mechanical properties, bond strength, freezethaw durability, impermeability, corrosion control and workability among others [4]. Chindaprasirit et al and Ha et al [5] confirmed that the incorporation of fly ash increases the porosity of the hardened cement paste at early stages, even though there is a reduction in the average pore size and this often results in a less permeable paste.

Tests conducted by Arya and Ofori-Darko [6], Glass et al [7] and Basheer et al [8] respectively on mortars containing ground granulated blasts slag (GGBS), indicated a prominent reduction in permeability and penetration of chlorides ions in specimens. The above mentioned authors [6-8] confirmed that the addition of GGBS influence the electromechanical response of pore solutions in cement system; this position is consistent with the finding of Daube et al when he observed that GGBS can be effective in reducing the pore size, [9] and cumulative pore volume considerably [10]. Compressive strength is a property that relates to other concrete properties and gives indication to its performance. Based on this, this article focus on early strength development of concrete specimens produced with various percentages (\%) composition of cementitious. 
The SCMs levels of $60 \%$ replacements was chosen for the present study and the results were compared with Ordinary Portland Cement (OPC) specimen without blended cements. Concrete specimens prepared with various SCMs \% replacement were evaluated against concrete specimen with $100 \%$ OPC for their compressive strengths at 7, 14, and 28 days. This study aims at investigating the effect of these SCMs combination on the strength development, not only from the compressive strength perspective as a design parameter for concrete structures, but also from the cost perspective and environmental sustainability point of view. The patronage of SCMs may reduce the release of substantial amount of pollution in the production of cement.

\section{Methodology}

\subsection{Materials and Experimental Procedures}

The main materials used are Ordinary Portland cement (OPC) with class $52.5 \mathrm{~N}$ conforming to South African Standards SANS 50197-1, Fly ash, Silica fume and Ground Granulated Blast-furnace slag (GGBS). OPC was obtained from Pretoria Portland Cement (PPC) South Africa, Fly ash was obtained from Ash Resources Lethabo plant located in Sasolburg, South Africa, Silica fume was obtained from Mapei South Africa, and Ground Granulated Blast-furnace Slag was obtained from Afrisam Vandebijilpark plant, South Africa. These SCMs were used as cement replacement in various proportions as indicated in Table 1 conforming to SANS 1491:1-3. Both fine (unwashed crusher sand) and coarse (22 mm) aggregates were obtained from Eikenhof plant of Afrisam cement, South Africa; while tap water available in the laboratory was used for casting and curing all concrete specimens. The water/blender (W/B) ratio was kept constant at 0.5 throughout the whole process. Fine and coarse aggregates quantities were also kept constant for all the design mixes while the cementitious blends were varied according to the study objective; the control specimen were kept at $100 \%$ OPC while other mixes contained different proportion of cementitious blends with OPC cement kept constant at $40 \%$ by mass of the cementitious materials as indicated in Table 1 . The sieve analyses of both coarse and fine aggregates were carried out in accordance with the SANS 201. The experiments were carried out at the concrete laboratory of the University of South Africa (UNISA).

\subsection{Mix Proportion and Preparation of the Specimen}

The test specimens were cast from 10 separate batches of concrete, one control and 9 mixes containing $40 \%$ of Portland cement, while the quantities of Silica fume, Fly ash and GGBS were varied accordingly. The mix design used for $1 \mathrm{~m} 3$ concrete is presented in Table 1.

Table 1: Mix Design for $1 \mathrm{~m}^{3}$ of concrete.

\begin{tabular}{|c|c|c|c|c|c|c|c|c|c|c|c|c|}
\hline \multirow[t]{3}{*}{ No. } & \multirow[t]{2}{*}{ MIX ID } & \multicolumn{4}{|c|}{ Cement Content by percentage } & \multicolumn{4}{|c|}{ Cement Content by mass } & \multirow{3}{*}{$\begin{array}{l}\text { Water } \\
\text { Content } \\
\left(\mathrm{kg} / \mathrm{m}^{3}\right)\end{array}$} & \multirow{3}{*}{$\begin{array}{l}\text { Fine } \\
\text { agg } \\
\text { content } \\
\left(\mathrm{kg} / \mathrm{m}^{3}\right)\end{array}$} & \multirow{2}{*}{$\begin{array}{l}\text { Coarse } \\
\text { agg } \\
\text { content } \\
\left(\mathrm{kg} / \mathrm{m}^{3}\right)\end{array}$} \\
\hline & & \multicolumn{4}{|c|}{$(\%)$} & \multicolumn{4}{|c|}{$\left(\mathrm{kg} / \mathrm{m}^{3}\right)$} & & & \\
\hline & & OPC & SF & FA & GGBS & OPC & SF & FA & GGBS & & & \\
\hline 1 & Control & 100 & - & - & - & 420 & - & - & - & 210 & 824.66 & 1091 \\
\hline 2 & CSFG4114 & 40 & 10 & 10 & 40 & 168 & 42 & 42 & 168 & 210 & 824.66 & 1091 \\
\hline 3 & CSFG4123 & 40 & 10 & 20 & 30 & 168 & 42 & 84 & 126 & 210 & 824.66 & 1091 \\
\hline 4 & CSFG4132 & 40 & 10 & 30 & 20 & 168 & 42 & 126 & 84 & 210 & 824.66 & 1091 \\
\hline 5 & CSFG4411 & 40 & 40 & 10 & 10 & 168 & 168 & 42 & 42 & 210 & 824.66 & 1091 \\
\hline 6 & CSFG4312 & 40 & 30 & 10 & 20 & 168 & 126 & 42 & 84 & 210 & 824.66 & 1091 \\
\hline 7 & CSFG4213 & 40 & 20 & 10 & 30 & 168 & 84 & 42 & 126 & 210 & 824.66 & 1091 \\
\hline 8 & CSFG4141 & 40 & 10 & 40 & 10 & 168 & 42 & 168 & 42 & 210 & 824.66 & 1091 \\
\hline 9 & CSFG4231 & 40 & 20 & 30 & 10 & 168 & 84 & 126 & 42 & 210 & 824.66 & 1091 \\
\hline 10 & CSFG4321 & 40 & 30 & 20 & 10 & 168 & 126 & 84 & 42 & 210 & 824.66 & 1091 \\
\hline
\end{tabular}

Cubic plastic mold of dimensions $150 \times 150 \times 150 \mathrm{~mm}$ conforming to SANS 5860:2006 was used for casting the concrete. Particle relative, Compacted Bulk Densities (CBD) of the aggregates and the Fineness Modulus (FM) of the fine aggregates were determined in accordance with SANS 5847 prior to the trial mix. The coarse and fine CBD was found to 
be $1648 \mathrm{~kg} / \mathrm{m} 3$ and $1860 \mathrm{~kg} / \mathrm{m} 3$ respectively while the FM of fine was found to be 3.68 . The \% Flakiness conducted in accordance to TMH1 B3T was found to be $16.06 \%$. Cement and Concrete Institute (C \& CI) method was used to design trial mix for the control sample thereby verifying any assumptions and eliminating significant inaccuracy usually accompany concrete design mix.

After casting, the concrete specimens were covered with polythene materials to prevent evaporation of the concrete specimens for proper curing for 24 hours prior to demolding. After demolding, the cubes were cured in a portable water curing bath under a controlled temperature range of $22-25^{\circ} \mathrm{C}$ for 7,14 , and 28 days respectively before testing.

The workability of the concrete specimens was measured using the slump cone test in accordance with SANS 58621:2006 [12]. After the slump test, the specimen molds were oiled and placed on a levelled vibrating table to be filled with the concrete mixture. The specimens were cast in accordance with SANS 5861-1:2006 [13]. Following the casting process, all instruments and equipment used were cleaned thoroughly including the mixer and prepared for the next mix. The description of the concrete specimens and the slump test result are presented in Table 2.

Table 2: Specimen Description and its Workability.

\begin{tabular}{|c|c|c|c|}
\hline Mix No & Mix ID & SCMs $\%$ Composition & $\begin{array}{c}\text { Slump } \\
(\mathrm{mm})\end{array}$ \\
\hline 1 & CCS & $100 \%$ OPC & 33 \\
\hline 2 & CSFG4114 & $40 \%$ OPC+10\%SF+10\%FA+40\%GGBS & 49 \\
\hline 3 & CSFG4123 & $40 \%$ OPC+10\%SF+20\%FA+30\%GGBS & 67 \\
\hline 4 & CSFG4132 & $40 \%$ OPC+10\%SF+30\%FA+20\%GGBS & 68 \\
\hline 5 & CSFG4411 & $40 \%$ OPC+40\%SF+10\%FA+10\%GGBS & 35 \\
\hline 6 & CSFG4312 & $40 \%$ OPC+30\%SF+10\%FA+20\%GGBS & 62 \\
\hline 7 & CSFG4213 & $40 \%$ OPC+20\%SF+10\%FA+30\%GGBS & 67 \\
\hline 8 & CSFG4141 & $40 \%$ OPC+10\%SF+40\%FA+10\%GGBS & 63 \\
\hline 9 & CSFG4231 & $40 \%$ OPC+20\%SF+30\%FA+10\%GGBS & 56 \\
\hline 10 & CSFG4321 & $40 \%$ OPC+30\%SF+20\%FA+10\%GGBS & 35 \\
\hline
\end{tabular}

\section{Results and Discussions}

\subsection{Effect of Supplementary Cementitious Materials on Compressive Strength}

The mixture of different supplementary materials produced substantial amount of compressive strength compared to the control sample at $100 \%$ OPC as shown in Figure 1. The combination of $30 \%$ silica fume, $20 \%$ fly ash, and $10 \%$ ggbs produced the highest compressive strength of $24.40 \mathrm{MPa}$, which is $43.4 \%$ of the control sample at 7 days while maintaining the OPC content at $40 \%$ of the mix composition, (Mix 10). However, the combination of $10 \%$ Silica fume, $20 \%$ Fly ash, and 30\% GGBS produced the highest strength of $41.12 \mathrm{Mpa}$ at 28 days which is $69 \%$ of the control sample strength (mix 3 ). It is also observed that the strength of Mix 2, 4 and 9 are in the range of between (20.20-24.40) Mpa; although, none of the mix performed below $16 \mathrm{MPa}$ at 7 days and $32 \mathrm{MPa}$ at 28 days. The results obtained showed that the rate of increase in strength as curing age progresses is higher for SCMs specimens than for the control specimen. These results give an indication that if the specimens were left for further curing ages, there is high possibility of higher compressive strength for the SCMs specimens compared to the control samples. The reported strength values represented the average strength of three specimens for each mix combination. The lower early strength obtained in the SCMs specimens compared to the control specimen can be attributed to the effect of the pozzolanic reactions on specimens containing SCMs. The results presented in this paper, are part of the ongoing project. Further studies on the effect of these SCMs on late compressive strength and their effect on corrosion are ongoing. 


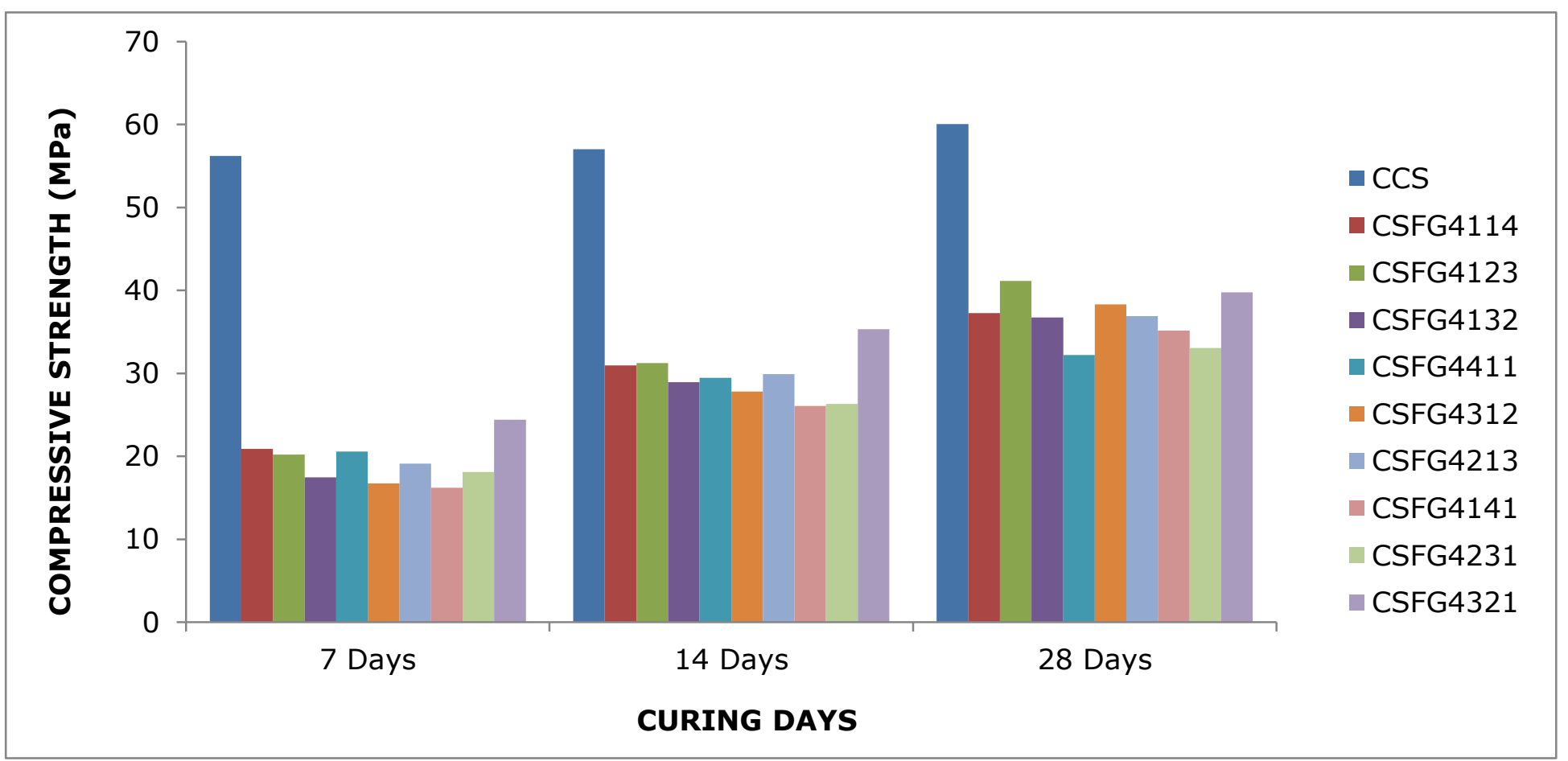

Fig. 1: Compressive Strength results of specimens.

\section{Conclusions}

This study focused primarily on the effects of different mix design containing varied supplementary cementitious blends on early strength development of concrete cured for a short period (28 days). The optimum compressive strength for SCMs specimens at 7 and 14 days was achieved for specimen 10 (CSFG4321), this was overtaken by specimen 3 (CSFG4123) at 28 days curing period. The combination of SCMs in the specimens showed interesting results that gave an indication that the later strengths of these specimens have the tendency to be higher than the control specimen. Further studies are ongoing to investigate the effect of the SCMs specimens on later compressive strength and corrosion.

\section{Acknowledgements}

The authors thank the University of South Africa for their support and making this research possible.

\section{References}

[1] H. Toutanji, N. Delatte and S. Aggoun, Effect of Supplementary cementitious materials on the compressive strengthand durability of short-term cured concrete. Cleveland State University, Civil and Environmental engineering faculty publications, 2004.

[2] B. D. Ikotun, G. C. Fanourakis and S. Mishra, "Effect of fly ash- $\beta$-cyclodextrin composites on concrete properties," in Proceedings of the first International Conference on Construction Materials and Structures, ISBN 978-1-61499465-7,825-834, 2014.

[3] A. R. Boga and I. B. Topcu, "Influence of fly ash on corrosion resistance and chloride ion permeability of concrete," Construction and Building Materials, vol.31, pp. 258-264, 2012.

[4] P. Chindaprasirit, C. Chotithanorm and V. Sirivivatnanon, "Influence of fly ash fineness on the chloride penetration of concrete," Construction Building Materials, 2007, vol. 21, pp. 356-61.

[5] S. Muralidharan and KW. Park, Accelerated short-term techniques to evaluate the corrosion performance of steel infly ash blended concrete, Building Environment, vol. 42, no. 78-85, 2007.

[6] C. Arya and F. K. Ofori-Darko, Cement and Concrete Research, vol.26, pp. 345, 1996.

[7] G. K. Glass, B. Reddy and N. R. Buenfeld, Corrosion Science, vol. 42, pp. 1587, 2000. 
[8] S. E. Chidac and A. E. Long, "Predictive models for deterioration of concrete structures," Construction Building Materials, vol. 10, pp. 27-37, 1996.

[9] J. R. Daube and R. Bakker, "Portland blast-furnace slag cements a review," in: Blended Cement, G. Fronhnsdorff (Ed.), ASTM Sp Tech. Publication No. 897, 1983.

[10] Y. S. Choi and J.-G. Kim, "Corrosion behaviour of steel bar embedded in fly ash concrete," Corrosion Sciencevol, 48, pp. 1733-1745, 2006.

[11] SANS 5862-1:2006, Concrete tests-consistence of freshly mixed concrete - slump test, Pretoria: South Africa Bureau of Standards.

[12] SANS 5861-1:2006 Concrete tests, Part 1: Mixing fresh concrete in the laboratory, ISBN 978-0-626-27128-2. Edition 2.1. 